\title{
Volatilização de amônia proveniente de fertilizantes minerais mistos contendo ureia
}

\author{
Gabriela Cemirames de Sousa Gurgel(1), Anderson Claiton Ferrari(1), Ademir Fontana(2), \\ José Carlos Polidoro ${ }^{(2)}$, Leonardo de Andrade Martins Coelho ${ }^{(1)}$ e Everaldo Zonta ${ }^{(1)}$
}

\begin{abstract}
(1)Universidade Federal Rural do Rio de Janeiro, Departamento de Solos, BR 465, Km 7, CEP 23897-000 Seropédica, RJ, Brasil. E-mail: gabriela_cemirames@hotmail.com, anderson.rural@hotmail.com, leonardoamcoelho@gmail.com, ezonta@ufrrj.br (2)Embrapa Solos, Rua Jardim Botânico, no 1024, Jardim Botânico, CEP 22460-000 Rio de Janeiro, RJ, Brasil. E-mail: jose.polidoro@embrapa.br, ademir.fontana@embrapa.br
\end{abstract}

Resumo - O objetivo deste trabalho foi selecionar um método para estimar o $\mathrm{N}-\mathrm{NH}_{3}$ perdido por volatilização e determinar essas perdas em fertilizantes mistos contendo ureia. Um experimento foi realizado em casa de vegetação, em bandejas preenchidas com solo arenoso, com as doses de ureia de $0,50,100$ e $200 \mathrm{~kg} \mathrm{ha}^{-1}$ de N. A amônia volatilizada foi quantificada por três métodos: CSA, coletor semiaberto; Sale, coletor semiaberto livre estático; e CA, coletor aberto. Em um segundo experimento, avaliou-se a volatilização de amônia proveniente de 18 fertilizantes mistos com ureia, ácidos húmicos e zeólita, em solos com textura arenosa e argilosa, na dose de $200 \mathrm{~kg} \mathrm{ha}^{-1}$ de N. O CSA foi o método que recuperou mais N, seguido do Sale e do CA. O Sale é mais adequado para experimentos com elevado número de unidades amostrais, por ser mais prático. Os fertilizantes minerais mistos com ureia e ácido húmico (5 e 10\%) e com ureia e zeólita (10\%) apresentaram os melhores resultados na mitigação da volatilização da amônia, com redução nas perdas de $\mathrm{N}^{-\mathrm{NH}_{3}}$ de até $38 \%$. Os tratamentos são mais efetivos no combate à volatilização no solo de textura arenosa.

Termos para indexação: ácidos húmicos, coletores semiabertos, fertilizantes nitrogenados, fertilizantes organominerais, perdas de $\mathrm{N}$, zeólita.

\section{Ammonia volatilization from mixed mineral fertilizers containing urea}

Abstract - The objective of this work was to select a method for estimating $\mathrm{N}-\mathrm{NH}_{3}$ lost by volatilization and to determine these losses in mixed fertilizers containing urea. An experiment was conducted in a greenhouse in trays filled with sandy soil, with urea rates of $0,50,100$, and $200 \mathrm{~kg} \mathrm{ha}^{-1} \mathrm{~N}$. Volatilized ammonia was quantified by three methods: CSA, semi-open collector; Sale, free and static semi-open collector; and CA, open collector. In a second experiment, volatilization of ammonia from 18 fertilizers mixed with urea, humic acids, and zeolite was evaluated in sandy and clayey soils, at $200 \mathrm{~kg} \mathrm{ha}^{-1} \mathrm{~N}$. CSA was the method with the highest $\mathrm{N}$ recovery, followed by Sale and CA. Sale is more suited for experiments with a high number of experimental units, since it is more practical. The mixed fertilizers with urea and humic acids (5 and $10 \%)$ and with urea and zeolite (10\%) had the best results in the mitigation of ammonia volatilization, reducing $\mathrm{N}-\mathrm{NH}_{3}$ losses in up to $38 \%$. The treatments are more effective in mitigating volatilization losses in the sandy soil.

Index terms: humic acids, semi-open collectors, nitrogen fertilizers, organic mineral fertilizers, $\mathrm{N}$ losses, zeolite.

\section{Introdução}

Os fertilizantes nitrogenados são insumos importantes para agricultura em razão de sua grande demanda para produção de alimentos, fibras e materiais energéticos. No Brasil, o consumo de fertilizantes nitrogenados é crescente, e o mercado brasileiro de fertilizantes movimentou, em 2014, 32,2 milhões de toneladas, um aumento de $4,9 \%$ em comparação a 2013 (Anda, 2015). A ureia é o fertilizante nitrogenado mais utilizado no Brasil (Tasca et al., 2011), em razão de sua elevada concentração de nitrogênio e, consequentemente, de seu baixo custo por quilograma de N.

Em cultivos agrícolas, a forma mais comum de aplicação da ureia no solo é em cobertura, sem incorporação, o que aumenta a possibilidade de perdas do nutriente por volatilização (Frazão et al., 2014). Dada a larga utilização desse fertilizante na agricultura, e o grande potencial de perdas do nitrogênio aplicado, 
pesquisas têm sido desenvolvidas para aumentar a eficiência de uso da ureia, principalmente com vistas à mitigação do processo de volatilização de amônia (Paiva et al., 2012; Faria et al., 2013; Frazão et al., 2014; Oliveira et al., 2014).

Nesse sentido, Faria et al. (2013) sugerem a aplicação de ureia juntamente com outros materiais que possam atuar na redução das perdas do $\mathrm{N}-\mathrm{NH}_{3}$ volatilizado; tais como sulfato de cobre, ácido bórico, zeólita e sulfato de amônio. A zeólita é um mineral que, adicionado à ureia, é capaz de atuar na redução das perdas de $\mathrm{N}-\mathrm{NH}_{3}$ em virtude da sua capacidade de reter íons, como o amônio $\left(\mathrm{NH}_{4}^{+}\right)$, e protegê-los fisicamente contra a volatilização (Englert \& Rubio, 2005; Bernardi et al., 2010). Oliveira et al. (2014) afirmam que a adição de fertilizantes com características ácidas pode reduzir as perdas de amônia por volatilização da ureia em até $29 \%$. Dessa forma, a formulação de fertilizantes nitrogenados a partir da adição de ácidos húmicos e zeólita à ureia pode reduzir as perdas de $\mathrm{N}$ e aumentar a eficiência agronômica desses fertilizantes (He et al., 2002; Latifah et al., 2011; Faria et al., 2013).

Para que se avalie a eficiência dos fertilizantes nitrogenados em fornecer $\mathrm{N}$ para as plantas, é necessário quantificar as perdas gasosas do nutriente bem como avaliar seu ciclo no sistema solo-plantaatmosfera (Alves, 2006). Com relação a isso, é desejável que os métodos para determinação da volatilização de $\mathrm{N}-\mathrm{NH}_{3}$ sejam de baixo custo e tenham pouca influência no processo.

Diante da necessidade de intensificação do uso de tecnologias para aumento da produtividade e redução do impacto ambiental, a avaliação de métodos de quantificação da volatilização de amônia oriunda de fertilizantes mistos contendo ureia é necessária para selecionar as combinações com maior potencial de mitigação da perda de $\mathrm{N}$.

Este trabalho teve como objetivo selecionar um método para estimar o $\mathrm{N}-\mathrm{NH}_{3}$ perdido por volatilização e avaliar diferentes fertilizantes mistos contendo ureia quanto à perda de $\mathrm{N}$ por volatilização de amônia.

\section{Material e Métodos}

Foram realizados dois ensaios em casa de vegetação, no Instituto de Agronomia da Universidade Federal Rural do Rio de Janeiro (UFRRJ), em Seropédica, RJ. $\mathrm{O}$ primeiro ensaio comparou métodos para estimativa das perdas de $\mathrm{N}-\mathrm{NH}_{3}$ volatilizado após a aplicação superficial de ureia ao solo. $O$ segundo ensaio quantificou as perdas de $\mathrm{N}$ de novos fertilizantes minerais mistos formulados com base na ureia, em dois solos, com texturas arenosa e argilosa.

No experimento 1, as unidades amostrais foram constituídas por bandejas plásticas $(39 \times 25 \times 7 \mathrm{~cm})$, e utilizou-se terra oriunda da camada superficial de um Planossolo Háplico, cuja análise revelou os seguintes valores: areia, $920 \mathrm{~g} \mathrm{~kg}^{-1}$; silte, $10 \mathrm{~g} \mathrm{~kg}^{-1}$; argila, $70 \mathrm{~g} \mathrm{~kg}^{-1}$; 0,05, 1,76, 0,9, 2,5, 0,5, $\mathrm{cmol}_{\mathrm{c}} \mathrm{dm}^{-3} \mathrm{de} \mathrm{Na}^{+}, \mathrm{Ca}^{2+}, \mathrm{Mg}^{2+}$, $\mathrm{H}+\mathrm{Al}, \mathrm{Al}^{3+}$, respectivamente; soma de bases (S) de 2,81; capacidade de troca catiônica $(\mathrm{T})$ de 5,$31 ; \mathrm{pH}_{\mathrm{H} 2 \mathrm{O}}$, 5,5; P-mehlich-1, 57,9 mg dm${ }^{-3}$; e K $, 39,3 \mathrm{mg} \mathrm{dm}^{-3}$.

A terra foi seca ao ar por 72 horas, homogeneizada e passada em peneira de $2 \mathrm{~mm}$ antes do preenchimento das bandejas, com capacidade de $7 \mathrm{~kg}$. O solo foi incubado com calcário dolomítico (PRNT=80\%), tendo-se elevado o $\mathrm{pH}$ a 6,5. A umidade foi mantida a $50 \%$ da capacidade de campo, com pesagens diárias para verificar a necessidade de aplicação de água. A água era adicionada às bandejas após a remoção do coletor, por ocasião da troca de posição destes.

O experimento foi conduzido por 22 dias, de 24 de março a 14 de abril de 2013. A temperatura e a umidade relativa do ar foram monitoradas diariamente com os dados da estação meteorológica instalada na casa de vegetação (Figura $1 \mathrm{~A}$ ).

Utilizou-se o delineamento experimental inteiramente casualizado, com 12 tratamentos e 3 repetições, no total de 36 parcelas experimentais. A ureia granulada $(45 \% \mathrm{~N})$ foi aplicada superficialmente nas bandejas, de maneira homogênea, e os coletores foram instalados em seguida. Foram utilizadas quatro doses do fertilizante, correspondentes a $0 ; 50 ; 100$; e $200 \mathrm{~kg} \mathrm{ha}^{-1}$ de N. Três métodos para captura da amônia volatilizada foram avaliados: CSA, coletor com câmara semiaberta (Nômmik, 1973, adaptado por Lara Cabezas et al., 1999); Sale, coletor com câmara semiaberta livre estática (Araújo et al., 2009); e CA, coletor aberto com absorvedor envolto em película de politetrafluoretileno (Mariano et al., 2012). Os coletores foram mudados de posição a cada coleta, para evitar a formação de microclima que pudesse interferir no processo de volatilização de amônia.

As perdas foram estimadas com a determinação do nitrogênio capturado nos coletores instalados, por meio de destilação e titulação. As espumas dos coletores foram trocadas diariamente, durante a primeira semana e, após isso, a cada três dias até o fim 
do experimento (total de 12 coletas). Após cada coleta, os discos de espuma dos coletores CSA e CA foram acondicionados em sacolas de plástico e levados ao laboratório para lavagem. As espumas foram lavadas com $450 \mathrm{ml}$ de água destilada, em funil acoplado à bomba de vácuo, e a solução obtida com a lavagem foi guardada em garrafas de plástico, na geladeira. No dia seguinte, foram recolhidas alíquotas de $50 \mathrm{ml}$ para determinação do nitrogênio $b$ em destilador automático UDK 159 Series (VELP Scientifica). No potes de $50 \mathrm{ml}$ com a solução ácida. Em seguida, foram adicionados $30 \mathrm{ml}$ de água, tendo-se agitado a solução por 15 minutos, em agitador horizontal, e retirado uma alíquota de $10 \mathrm{ml}$ para determinação do nitrogênio no mesmo destilador. Para o cálculo do $\mathrm{N}$ volatilizado, foram empregados fatores de correção indicados em cada método, de acordo com a área da bandeja.

Os dados foram submetidos à análise de variância, e as médias dos teores de $\mathrm{N}$ foram comparadas com o teste Tukey, a 5\% de probabilidade. As doses de ureia avaliadas foram ajustadas a modelos de regressão, cujos coeficientes foram testados com o teste $\mathrm{t}$, a $1 \%$ de probabilidade. Utilizou-se o Saeg 9.1 (Universidade Federal de Viçosa, Viçosa) para as análises estatísticas.

No experimento 2, o local do experimento, os procedimentos de preparo do solo, as unidades experimentais, e os procedimentos de captura do $\mathrm{N}$ volatilizado e de determinação do $\mathrm{N}$ seguiram a descrição do experimento anterior.

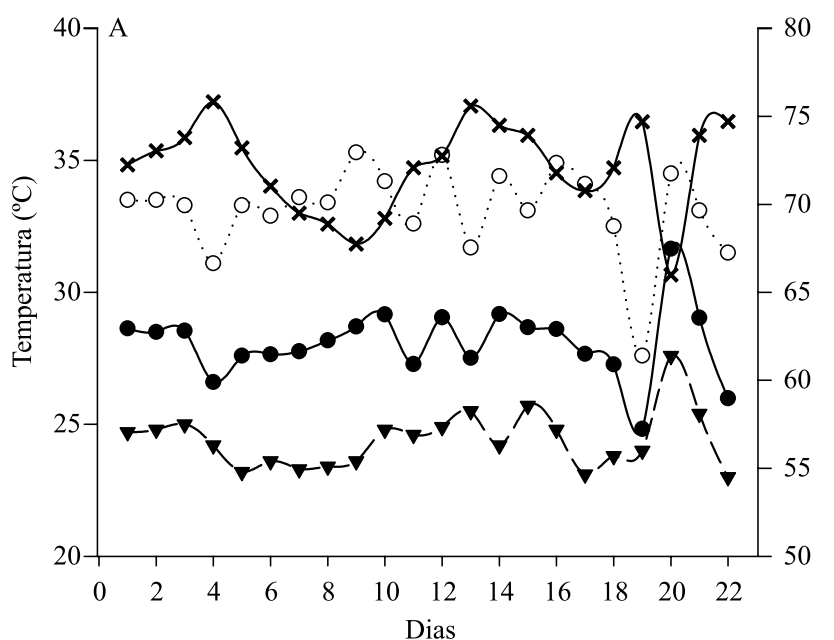
caso do coletor Sale, as espumas foram coletadas em

Nas bandejas, a terra foi proveniente da camada superficial do Planossolo Háplico de textura arenosa, o mesmo utilizado no experimento $1 \mathrm{e}$, ainda, da camada superficial de um Latossolo Vermelho de textura argilosa, cuja análise revelou os seguintes valores: areia, $180 \mathrm{~g} \mathrm{~kg}^{-1}$; silte, $20 \mathrm{~g} \mathrm{~kg}^{-1}$; argila, $800 \mathrm{~g}$ $\mathrm{kg}^{-1} ; 0,29,0,60,0,30,3,8,0,3, \mathrm{cmol}_{\mathrm{c}} \mathrm{dm}^{-3} \mathrm{de} \mathrm{Na}^{+}, \mathrm{Ca}^{2+}$, $\mathrm{Mg}^{2+}, \mathrm{H}+\mathrm{Al}, \mathrm{Al}^{3+}$, respectivamente; soma de bases (S) de 1,2; capacidade de troca catiônica (T) de 5,0; $\mathrm{pH}_{\mathrm{H} 2 \mathrm{O}}, 5,7$; P-mehlich-1, 4,0 mg dm dm $^{-3}$ e $\mathrm{K}^{+}, 2,8 \mathrm{mg}$ $\mathrm{dm}^{-3}$. As condições de temperatura e umidade estão apresentadas na Figura 1 B. O trabalho foi conduzido no período de 10 de agosto a 1 de setembro de 2014 .

Utilizou-se o delineamento experimental inteiramente casualizado, e os tratamentos consistiram da aplicação de 18 fertilizantes minerais mistos baseados na ureia (Tabela 1), na dose correspondente a $200 \mathrm{~kg} \mathrm{ha}^{-1}$ de N, nos dois solos. Foram utilizadas três repetições para cada tratamento, além de um controle, no total de 111 unidades experimentais.

Os fertilizantes mistos foram preparados em laboratório com adição de zeólita cubana e ácidos húmicos. Os ácidos húmicos foram extraídos em laboratório, por meio de procedimento previamente desenvolvido para cada material em particular, com a determinação da concentração da solução extratora e relação massa/volume a serem empregados. As fontes das quais foram extraídos os ácidos húmicos utilizados na composição dos fertilizantes foram dois produtos comerciais distintos. Os fertilizantes foram aplicados

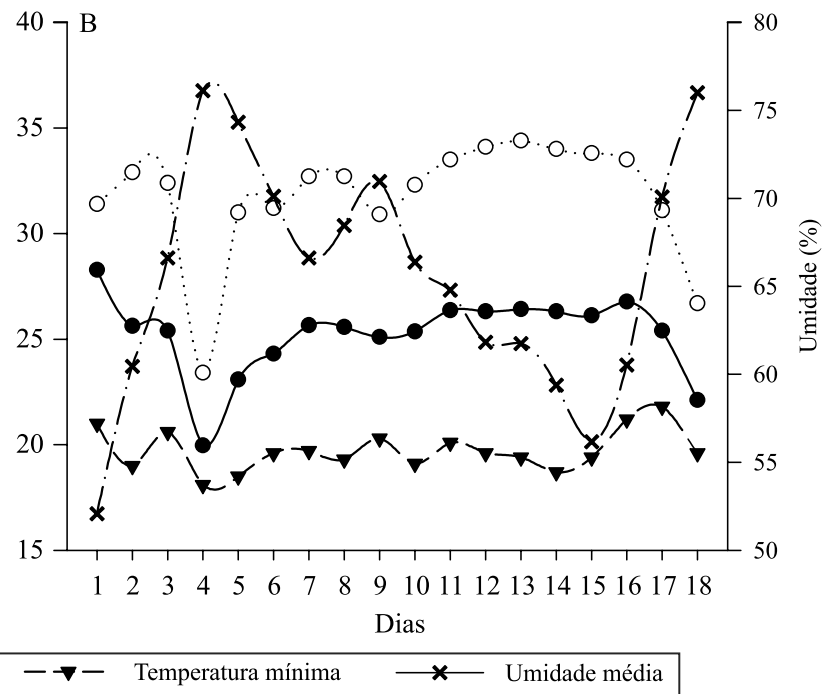

Figura 1. Temperatura e umidade registradas em casa de vegetação durante o período de condução dos experimentos 1 (A) e 2 (B).

Pesq. agropec. bras., Brasília, v.51, n.9, p.1686-1694, set. 2016 DOI: 10.1590/S0100-204X2016000900069 
de forma homogênea em toda a superfície da bandeja e, logo após, foram instalados dois coletores do tipo Sale por bandeja, conforme já descrito para o experimento 1. As avaliações foram feitas por 18 dias, com a troca diária das espumas durante os seis primeiros dias, e com trocas a intervalos de três dias a partir de então, até o fim do experimento, num total de 10 coletas.

Os teores de $\mathrm{N}$ foram submetidos à análise de variância e as médias foram comparadas com o teste Scott-Knott, a 5\% de probabilidade, tendo-se utilizado o programa $\mathrm{R}$ para as análises.

\section{Resultados e Discussão}

Os métodos de coleta do $\mathrm{N}-\mathrm{NH}_{3}$ volatilizado não diferiram entre si para as menores doses de ureia comercial granulada utilizadas (0 e $50 \mathrm{~kg} \mathrm{ha}^{-1}$ de N). Para as doses de 100 e $200 \mathrm{~kg} \mathrm{ha}^{-1}$, o CSA diferiu estatisticamente do Sale e do $\mathrm{CA}$, os quais não diferiram entre si. O CSA recuperou 29,3, 29,48 e $25,0 \%$ do nitrogênio total aplicado, para as doses de 50,100 e $200 \mathrm{~kg} \mathrm{ha}^{-1}$ de $\mathrm{N}$, respectivamente. Para o Sale, a recuperação foi de $16,79,13,06$ e $16,65 \%$ do N total aplicado, e, para o CA, a recuperação foi de 15,02, 16,28 e 12,02\%. Esses valores de recuperação da amônia volatilizada são menores do que os relatados em alguns estudos na literatura. Essa diferença,

Tabela 1. Descrição dos fertilizantes nitrogenados formulados com ureia e adição de ácidos húmicos e zeólita, em diferentes proporções.

\begin{tabular}{lc}
\hline Fertilizante $^{(1)}$ & Descrição do tratamento \\
\hline Ureia + AH 2,5 F1 & Ureia + Ácido húmico (2,5\%) F1 \\
Ureia + AH 5 F1 & Ureia + Ácido húmico (5\%) F1 \\
Ureia + AH 10 F1 & Ureia + Ácido húmico (10\%) F1 \\
Ureia + AH 20 F1 & Ureia + Ácido húmico (20\%) F1 \\
Ureia + AH 2,5 F2 & Ureia + Ácido húmico (2,5\%) F2 \\
Ureia + AH 5 F2 & Ureia + Ácido húmico (5\%) F2 \\
Ureia + AH 10 F2 & Ureia + Ácido húmico (10\%) F2 \\
Ureia + AH 20 F2 & Ureia + Ácido húmico (20\%) F2 \\
Ureia + Zeólita 2,5 & Ureia + Zeólita (2,5\%) \\
Ureia + Zeólita 5 & Ureia + Zeólita (5\%) \\
Ureia + Zeólita 10 & Ureia + Zeólita (10\%) \\
Ureia + Zeólita 20 & Ureia + Zeólita (20\%) \\
UAZ 1 & $10 \%$ de ácido húmico (F1) + 10\% de Zeólita \\
UAZ 2 & $5 \%$ de ácido húmico (F1) + 15\% de Zeólita \\
UAZ 3 & $15 \%$ de ácido húmico (F1) + 5\% de Zeólita \\
UAZ 4 & $10 \%$ de ácido húmico (F2) + 10\% de Zeólita \\
UAZ 5 & $5 \%$ de ácido húmico (F2) + 15\% de Zeólita \\
UAZ 6 & $15 \%$ de ácido húmico (F2) + 5\% de Zeólita \\
\hline
\end{tabular}

${ }^{(1)}$ As fontes 1 (F1) e 2 (F2) de ácido húmico referem-se a produtos comerciais de origens distintas. possivelmente, é reflexo do procedimento de correção da umidade da terra, utilizado no presente estudo, que teria favorecido a incorporação do fertilizante nos primeiros dias após a adubação. Alves et al. (2011) observaram estimativas de perda acumulada de $\mathrm{N}-\mathrm{NH}_{3}$ semelhantes entre as obtidas utilizando-se o CSA e as obtidas com a utilização do absorvedor de espuma posicionado a $1 \mathrm{~cm}$ do solo (tratamento correspondente ao CA neste trabalho), ou com o método do balanço de ${ }^{15} \mathrm{~N}$. Os autores sugeriram não ser necessário o uso de equações de calibração ou de fatores de correção para o CA.

Entretanto, observou-se água condensada nas paredes do CSA no presente trabalho, o que está relacionado à ocorrência de microclima que pode interferir no processo de volatilização da amônia. Esse microclima foi formado mesmo com o rodízio realizado na posição dos coletores, com o intuito de minimizar esse efeito.

Os métodos de quantificação do $\mathrm{N}-\mathrm{NH}_{3}$ apresentaram comportamentos semelhantes ao longo do tempo, com pico de volatilização por volta do segundo dia e perdas totais acumuladas mais expressivas até o quarto dia de avaliação (Figura 2). Uma vez que os métodos avaliados apresentaram comportamentos semelhantes, tendo diferido somente quanto à magnitude dos valores recuperados, todos eles podem ser utilizados na comparação dos fertilizantes minerais mistos propostos. Porém, o método Sale mostrou-se o mais adequado para condução de experimentos com número elevado de unidades amostrais, com maior praticidade desde o preparo das armadilhas ácidas até a coleta e análise das amostras.

Oliveira et al. (2008) verificaram valores de recuperação em torno de 25 e $20 \%$ com o emprego dos coletores semiaberto e aberto, respectivamente. Já Mariano et al. (2012), ao estimarem as perdas de N provenientes da ureia aplicada sobre palhada de cana com o coletor aberto, observaram perdas de até $24 \%$ da dose aplicada.

A melhor correlação entre as perdas acumuladas de $\mathrm{N}_{-} \mathrm{NH}_{3}$ e as doses de $\mathrm{N}$ avaliadas foi obtida com o uso de modelo linear, independentemente do método estudado para determinação das perdas de $\mathrm{N}$ (Figura 2).

$\mathrm{Na}$ avaliação dos fertilizantes minerais mistos formulados com base na ureia, os tratamentos tiveram maior expressão sobre a redução das perdas quando 

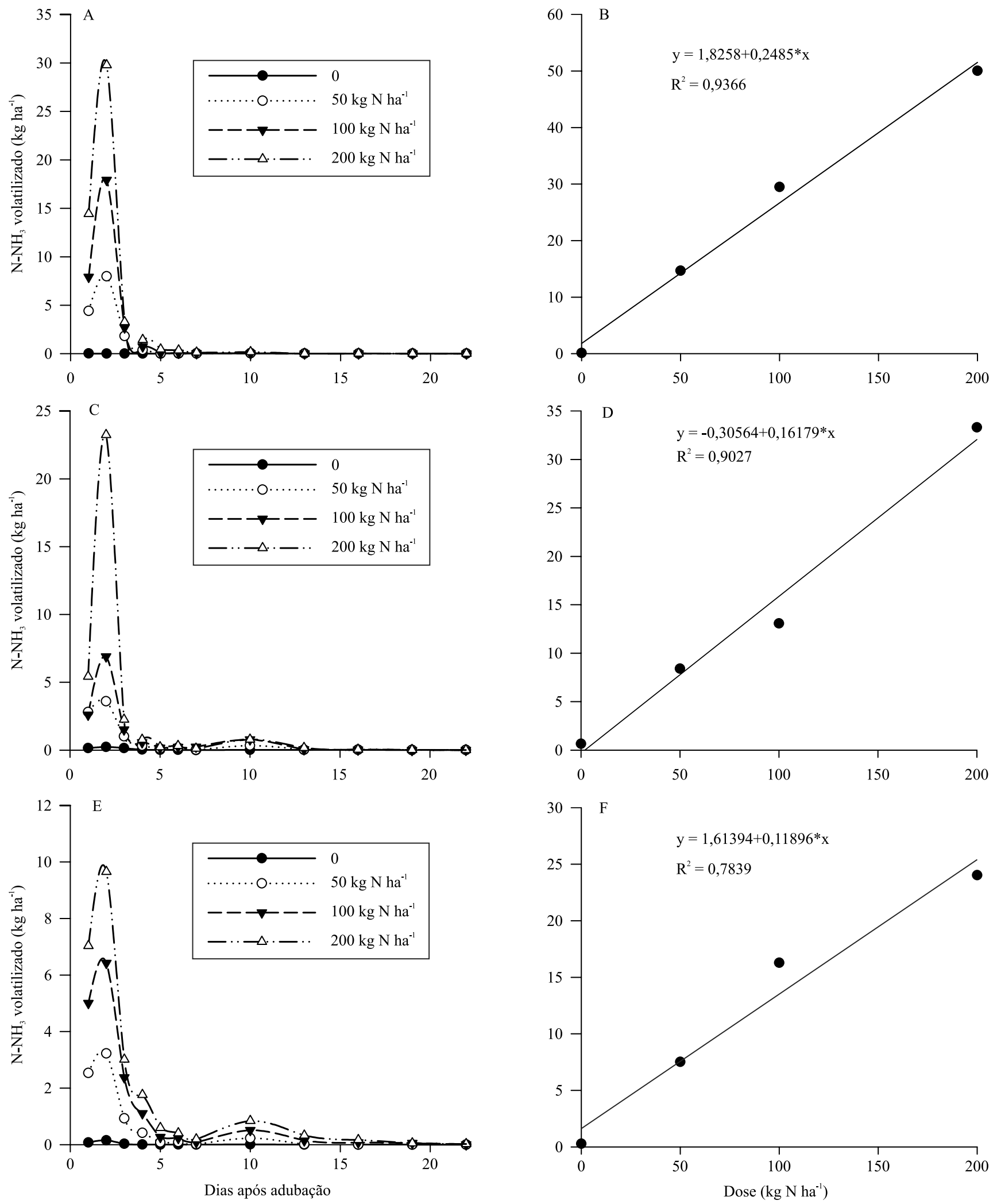

Figura 2. Perdas diárias de $\mathrm{N}-\mathrm{NH}_{3}$ volatilizado e capturado pelas armadilhas ácidas dos coletores: CSA, coletor com câmara semiaberta (A); Sale, coletor com câmara semiaberta livre estática (C); CA, coletor aberto com absorvedor envolto em película de politetrafluoretileno (E); e valores estimados das perdas acumuladas de N pelos métodos CSA (B), Sale (D) e CA (F). 
aplicados no solo arenoso (Figura 3), que apresentou condições mais favoráveis ao processo de volatilização. A reduçãonas perdas, noentanto, esteve mais relacionada à textura do solo do que ao efeito dos tratamentos.

As menores perdas de $\mathrm{N}$ foram observadas no tratamento Ureia + AH 5 F1 (ureia com adição de 5\% de ácido húmico extraído da fonte 1), Ureia + AH 10 F2 (ureia com adição de $10 \%$ de ácido húmico extraído da fonte 2) e Ureia + Zeólita 10 (ureia com adição de 10\% de zeólita), com 42,08, 42,33 e 43,78\% de perdas acumuladas ao final de 18 dias de avaliação, respectivamente. Isso representou uma redução nas perdas em torno de $38 \%$, em comparação ao tratamento menos eficiente.

A adição dos componentes retardou o pico de volatilização da amônia, em comparação ao experimento 1, que, de maneira geral, passou do segundo para o quarto dia após a adubação.

Costa et al. (2003), ao estudarem a volatilização de fontes nitrogenadas em cana-de-açúcar, em condições de campo, com colheita mecânica sem queima, registraram que as perdas ocorreram até os seis primeiros dias após a aplicação dos fertilizantes, em que a ureia, a ureia com adição de sulfato de amônio, o uran e um resíduo líquido enriquecido com nitrogênio apresentaram $36 ; 35 ; 15$; e $9 \%$ de perdas, respectivamente. Alves et al. (2011) também relataram pico de volatilização para ureia no sexto dia, com as perdas mais expressivas entre o quarto e o décimo dia.

A utilização simultânea de ácidos húmicos e zeólita apresentou um total de nitrogênio volatilizado acumulado ao fim de 18 dias de avaliação de até $57 \%$ para o solo arenoso, e de $35 \%$ para o argiloso, e esteve entre os tratamentos menos eficientes na redução da volatilização. Os resultados são contrários à expectativa gerada pela utilização conjunta dos componentes, já que se esperava efeito sinérgico da retenção do íon amônio pela zeólita e da redução do pH pela presença dos ácidos húmicos.

De acordo com Dong et al. (2009), pouco se sabe sobre o mecanismo pelo qual as substâncias húmicas aumentam a eficiência da fertilização com ureia. Os autores sugerem, no entanto, que a atuação dessas substâncias se dá de duas maneiras: pela incorporação de parte do amônio gerado às estruturas dos ácidos húmicos e pela inibição da atividade da urease. Contudo, estudos ainda devem ser realizados para que seja possível determinar com precisão o efeito de cada uma dessas substâncias, usadas de forma isolada ou paralela.

Latifah et al. (2011) investigaram o efeito da mistura da ureia com zeólita e turfa sobre as perdas de amônia e teores de amônio trocável no solo, em condição não alagada, e constataram que as misturas reduziram significativamente as perdas. De acordo com He et al. (2002), a aplicação de ureia, juntamente com celulose e zeólita, foi a mistura mais eficiente para reduzir as perdas por volatilização.

A adição de ácidos húmicos à ureia, nas diferentes proporções, ocasionou redução nas perdas de 42 a $68 \%$ do $\mathrm{N}$ total aplicado, no solo de textura arenosa, e de 24 a 35\%, no solo de textura argilosa (Tabela 2). Os ácidos húmicos podem atuar no tamponamento do $\mathrm{pH}$ ao redor do grânulo de ureia no momento da hidrólise, o que impediria que se atingissem valores de $\mathrm{pH}$ muito elevados, que são determinantes para desencadear o processo de volatilização. Os ácidos húmicos apresentam elevada CTC, característica que também está relacionada à manutenção do $\mathrm{N}$ no solo, pela adsorção do íon amônio $\left(\mathrm{NH}_{4}^{+}\right)$.

Paiva et al. (2012) utilizaram carvão oxidado de eucalipto no revestimento da ureia, para o controle da volatilização. $\mathrm{O}$ material foi caracteristicamente ácido $(\mathrm{pH}=2)$ e apresentou grande quantidade de grupos funcionais carboxílicos. Os autores relataram redução de $43 \%$ na quantidade de amônia volatilizada, em comparação à ureia sem o revestimento.

Para os tratamentos que continham a zeólita, a determinação do $\mathrm{N}-\mathrm{NH}_{3}$ pelos coletores indicou recuperação entre 44 e $60 \%$ do total de $\mathrm{N}$ aplicado, no solo arenoso, e de 25 a 33\%, no solo argiloso.

Bernardi et al. (2010) afirmam que o emprego de zeólita na fertilização nitrogenada reduz as perdas de $\mathrm{N}$ e proporciona rendimentos equivalentes à utilização de ureia com o inibidor NBPT, na cultura do azevém.

Ahmed et al. (2010) reportaram que, além de melhorar a retenção de amônio trocável no solo, a inclusão de zeólita na mistura com a ureia pode reduzir a conversão de amônio a nitrato. No entanto, Faria et al. (2013), ao avaliarem as perdas de $\mathrm{N}-\mathrm{NH}_{3}$ de fertilizantes nitrogenados aplicados em palhada de milho e soja, em plantio direto, não observaram efeito da adição de $15 \%$ de zeólita $(\mathrm{m} / \mathrm{m})$ à ureia, na redução nas perdas, em comparação com a ureia sem aditivos.

Pesq. agropec. bras., Brasília, v.51, n.9, p.1686-1694, set. 2016 DOI: 10.1590/S0100-204X2016000900069 

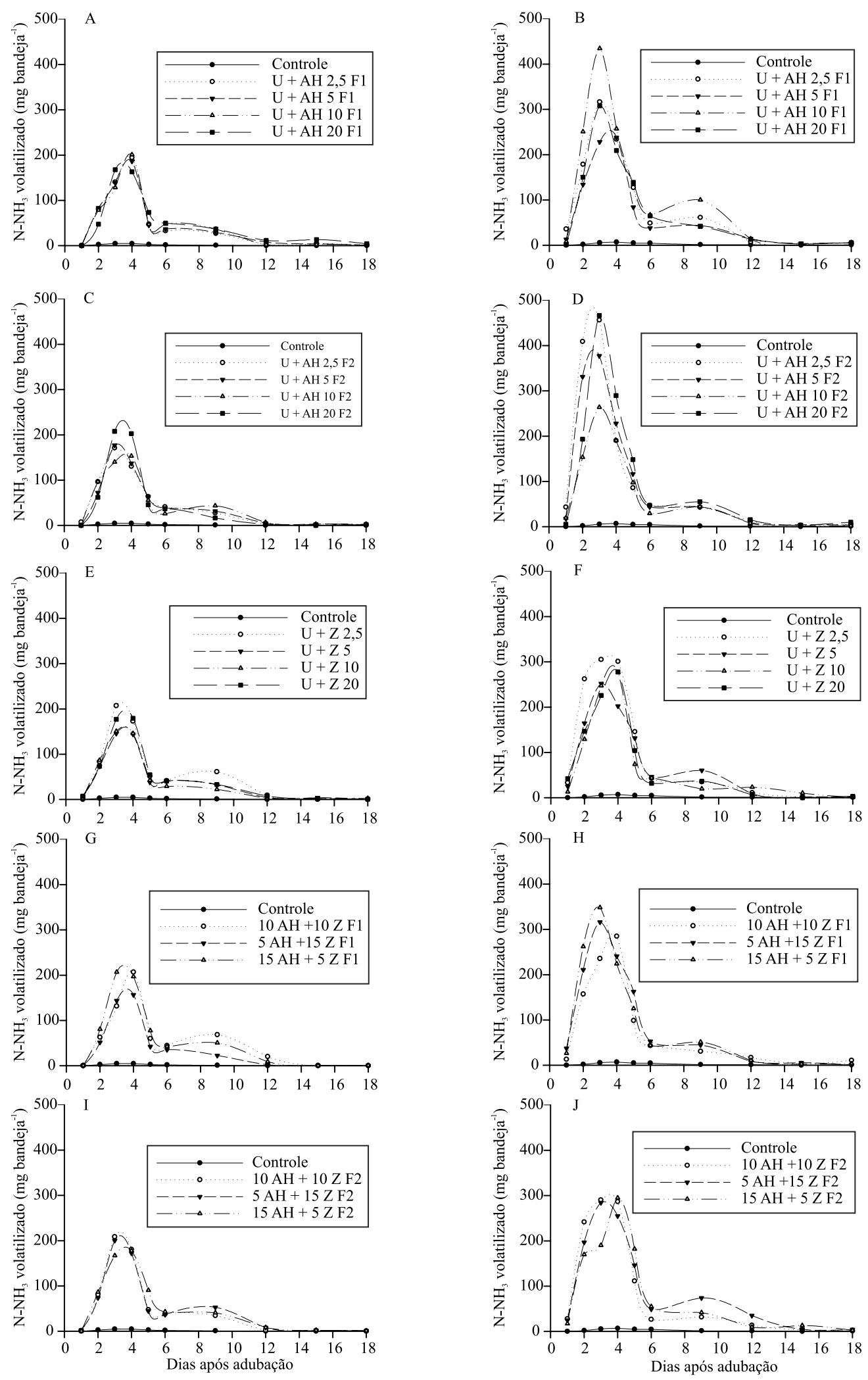

Figura 3. Perdas diárias de N-NH 3 volatilizado e capturado pelas armadilhas ácidas no coletor Sale, para os diferentes fertilizantes nitrogenados formulados com ureia e adição de ácidos húmicos e zeólita (Tabela 1), em diferentes proporções, na dose de $200 \mathrm{~kg} \mathrm{ha}^{-1} \mathrm{~N}$, em solo argiloso (coluna à esquerda) e arenoso (coluna à direita). 
Tabela 2. Perdas acumuladas de $\mathrm{N}^{-\mathrm{NH}_{3}}$ volatilizado resultante da aplicação superficial de fertilizantes formulados com ureia e adição de ácido húmico e zeólita em diferentes proporções, após 18 dias de avaliação, em solos com texturas diferentes ${ }^{(1)}$.

\begin{tabular}{|c|c|c|c|c|}
\hline \multirow[b]{2}{*}{ Fertilizante $^{(2)}$} & \multicolumn{2}{|c|}{ Solo arenoso } & \multicolumn{2}{|c|}{ Solo argiloso } \\
\hline & $\begin{array}{c}\mathrm{N}-\mathrm{NH}_{3} \\
\text { (mg por bandeja) }\end{array}$ & $\begin{array}{c}\text { Perdas } \\
(\%)\end{array}$ & $\begin{array}{c}\mathrm{N}-\mathrm{NH}_{3} \\
\text { (mg por bandeja) }\end{array}$ & $\begin{array}{c}\text { Perdas } \\
(\%)\end{array}$ \\
\hline $\mathrm{U}+\mathrm{AH} 2,5 \mathrm{~F} 1$ & $1.017,58 \mathrm{Fa}$ & 53,28 & $532,15 \mathrm{Cb}$ & 27,86 \\
\hline $\mathrm{U}+\mathrm{AH} 5 \mathrm{~F} 1$ & $803,82 \mathrm{Ia}$ & 42,08 & $533,99 \mathrm{Cb}$ & 27,96 \\
\hline $\mathrm{U}+\mathrm{AH} 10 \mathrm{~F} 1$ & $1.274,43 \mathrm{Aa}$ & 66,72 & $544,07 \mathrm{Cb}$ & 28,49 \\
\hline $\mathrm{U}+\mathrm{AH} 20 \mathrm{~F} 1$ & $937,86 \mathrm{Ga}$ & 49,10 & $568,01 \mathrm{Bb}$ & 29,74 \\
\hline $\mathrm{U}+\mathrm{AH} 2,5 \mathrm{~F} 2$ & $1.296,11 \mathrm{Aa}$ & 67,86 & $543,11 \mathrm{Cb}$ & 28,44 \\
\hline $\mathrm{U}+\mathrm{AH} 5 \mathrm{~F} 2$ & $1.177,34 \mathrm{Ca}$ & 61,64 & $531,50 \mathrm{Cb}$ & 27,83 \\
\hline $\mathrm{U}+\mathrm{AH} 10 \mathrm{~F} 2$ & $808,46 \mathrm{Ia}$ & 42,33 & $526,02 \mathrm{Cb}$ & 27,54 \\
\hline $\mathrm{U}+\mathrm{AH} 20 \mathrm{~F} 2$ & $1.234,93 \mathrm{Ba}$ & 64,66 & $576,57 \mathrm{Bb}$ & 30,19 \\
\hline$U+Z 2,5$ & $1.140,98 \mathrm{Da}$ & 59,74 & $631,76 \mathrm{Ab}$ & 33,08 \\
\hline $\mathrm{U}+\mathrm{Z} 5$ & $895,35 \mathrm{Ha}$ & 46,88 & $489,77 \mathrm{Db}$ & 25,64 \\
\hline $\mathrm{U}+\mathrm{Z} 10$ & $836,20 \mathrm{Ia}$ & 43,78 & $484,86 \mathrm{Db}$ & 25,39 \\
\hline $\mathrm{U}+\mathrm{Z} 20$ & $875,74 \mathrm{Ha}$ & 45,85 & $576,34 \mathrm{Bb}$ & 30,17 \\
\hline UAZ1 (10/10 F1) & $894,56 \mathrm{Ha}$ & 46,84 & $595,68 \mathrm{Bb}$ & 31,19 \\
\hline UAZ2 (5/15 F1) & $1.080,25 \mathrm{Ea}$ & 56,56 & $456,95 \mathrm{Db}$ & 23,92 \\
\hline UAZ3 (15/5 F1) & $1.097,38 \mathrm{Ea}$ & 57,45 & $664,45 \mathrm{Ab}$ & 34,79 \\
\hline UAZ4 (10/10 F2) & $1.034,83 \mathrm{Ea}$ & 54,18 & $595,26 \mathrm{Bb}$ & 31,17 \\
\hline UAZ5 (5/15 F2) & $1.075,18 \mathrm{Ea}$ & 56,29 & $595,30 \mathrm{Bb}$ & 31,17 \\
\hline UAZ6 (15/5 F2) & $974,80 \mathrm{Ga}$ & 51,04 & $616,57 \mathrm{Ab}$ & 32,28 \\
\hline
\end{tabular}

(1)Médias seguidas por letras iguais, maiúscula nas colunas e minúscula nas linhas, não diferem pelo teste de Scott-Knott, a 5\% de probabilidade. ${ }^{(2)}$ Os fertilizantes estão descritos na Tabela 1.

\section{Conclusões}

1. O método Sale é o mais recomendado para condução de experimentos com elevado número de unidades amostrais, pois apresenta facilidades desde o preparo dos coletores até coleta e análise das amostras.

2. Os fertilizantes minerais mistos com ureia e com adição de $5 \%$ de ácido húmico, extraído da fonte 1 , e $10 \%$, extraído da fonte 2 , bem como com a adição de $10 \%$ de zeólita, apresentaram os melhores resultados na mitigação da volatilização da amônia, com redução de até $38 \%$ nas perdas de $\mathrm{N}-\mathrm{NH}_{3}$.

3. Os tratamentos avaliados são mais expressivos no combate à volatilização no solo de textura arenosa.

\section{Agradecimentos}

À Coordenação de Aperfeiçoamento de Pessoal de Nível Superior (Capes), pela concessão de bolsas de estudos.

\section{Referências}

AHMED, O.H.; YAP, C.H.B.; MUHAMAD, A.M.N. Minimizing ammonia loss from urea through mixing with zeolite and acid sulphate soil. International Journal of the Physical Sciences, v.5, p.2198-2202, 2010.

ALVES, A.C. Métodos para quantificar a volatilização de N-NH ${ }_{3}$ em solo fertilizado com ureia. 2006. 40p. Dissertação (Mestrado) - Universidade de São Paulo, Pirassununga.

ALVES, A.C.; OLIVEIRA, P.P.A.; HERLING, V.R.; TRIVELIN, P.C.O.; LUZ, P.H. de C.; ALVES, T.C.; ROCHETTI, R.C.; BARIONI JUNIOR, W. New methods to quantify $\mathrm{NH}_{3}$ volatilization from fertilized surface soil with urea. Revista Brasileira de Ciência do Solo, v.35, p.133-140, 2011. DOI: 10.1590/S0100-06832011000100012.

ANDA. ASSOCIAÇÃO NACIONAL PARA DIFUSÃO DE ADUBOS. Principais indicadores do setor de fertilizantes: comentários. Disponível em: <http://www.anda.org.br/index. php?mpg=03.00.00>. Acesso em: 30 ago. 2015.

ARAÚJO, E. da S.; MARSOLA, T.; MIYAZAWA, M.; SOARES, L.H. de B.; URQUIAGA, S.; BODDEY, R.M.; ALVES,B.J.R. Calibração de câmara semiaberta estática para quantificação de amônia volatilizada do solo. Pesquisa Agropecuária Brasileira, v.44, p.769-776, 2009. DOI: 10.1590/S0100-204X2009000700018.

BERNARDI, A.C. de C.; MOTA, E.P. da; SOUZA, S. do C. H. de; CARDOSO, R.D.; OLIVIERA, P.P.A. Ammonia volatilization, dry matter yield and nitrogen levels of Italian ryegrass fertilized with urea and zeolite. In: WORLD CONGRESS OF SOIL SCIENCE, 19., 2010, Brisbane, Australia. Soil solutions for a changing world: anais. Brisbane: ASSSI, 2010. p.22-25.

COSTA, M.C.G.; VITTI, G.C.; CANTARELLA, H. Volatilização de $\mathrm{N}-\mathrm{NH}_{3}$ de fontes nitrogenadas em cana-de-açúcar colhida sem despalha a fogo. Revista Brasileira de Ciência do Solo, v.27, p.631-637, 2003. DOI: 10.1590/S0100-06832003000400007.

DONG, L.; CÓRDOVA-KREYLOS, A.L.; YANG, J.; YUAN, H.; SCOW, K.M. Humic acids buffer the effects of urea on soil ammonia oxidizers and potential nitrification. Soil Biology and Biochemistry, v.41, p.1612-1621, 2009. DOI: 10.1016/j. soilbio.2009.04.023.

ENGLERT, A.H.; RUBIO, J. Characterization and environmental application of a Chilean natural zeolite. International Journal of Mineral Processing, v.75, p.21-29, 2005. DOI: 10.1016/j. minpro.2004.01.003.

FARIA, L. de A.; NASCIMENTO, C.A.C. do; VITTI, G.C.; LUZ, P.H. de C.; GUEDES, E.M.S. Loss of ammonia from nitrogen fertilizers applied to maize and soybean straw. Revista Brasileira de Ciência do Solo, v.37, p.969-975, 2013.

FRAZÃO, J.J.; SILVA, A.R. da; SILVA, V.L. da; OLIVEIRA, V.A.; CORREA, R.S. Fertilizantes nitrogenados de eficiência aumentada e ureia na cultura do milho. Revista Brasileira de Engenharia Agrícola e Ambiental, v.18, p.1262-1267, 2014. DOI: 10.1590/1807-1929/agriambi.v18n12p1262-1267.

HE, Z.L.; CALVERT, D.V.; ALVA, A.K.; LI, Y.C.; BANKS, D.J. Clinoptilolite zeolite and cellulose amendments to reduce

Pesq. agropec. bras., Brasília, v.51, n.9, p.1686-1694, set. 2016 DOI: 10.1590/S0100-204X2016000900069 
ammonia volatilization in a calcareous sandy soil. Plant and Soil, v.247, p.253-260, 2002. DOI: 10.1023/A:1021584300322.

LARA CABEZAS, A.R.; TRIVELIN, P.C.O.; BENDASSOLI, J.A.; SANTANA, D.G. de; GASCHO, G.J.Calibration of a semi-open static collector for determination of ammonia volatilization from nitrogen fertilizers. Communications in Soil Science and Plant Analysis, v.30, p.389-406, 1999. DOI: 10.1080/00103629909370211.

LATIFAH, O.; AHMED, O.H.; MAJID, N.M. Ammonia loss, soil exchangeable ammonium and available nitrate contents from mixing urea with zeolite and peat soil water under nonwaterlogged condition. International Journal of the Physical Sciences, v.6, p.2916-2920, 2011.

MARIANO, E.; TRIVELIN, P.C.O.; VIEIRA, M.X.; LEITE, J.M.; OTTO, R.; FRANCO, H.C.J. Ammonia losses estimated by an open collector from urea applied to sugarcane straw. Revista Brasileira de Ciência do Solo, v.36, p.411-419, 2012.

NÔMMIK, H. The effect of pellet size on the ammonia loss from urea applied to forest soil. Plant and Soil, v.39, p.309-318, 1973. DOI: $10.1007 / \mathrm{BF} 00014798$.
OLIVEIRA, J.A. de; STAFANATO, J.B.; GOULART, R. de S.; ZONTA, E.; LIMA, E.; MAZUR, N.; PEREIRA, C.G.; SOUZA, H.N. de; COSTA, F.G.M. Volatilização de amônia proveniente de ureia compactada com enxofre e bentonita, em ambiente controlado. Revista Brasileira de Ciência do Solo, v.38, p.15581564, 2014. DOI: 10.1590/S0100-06832014000500021.

OLIVEIRA, P.P.A.; TRIVELIN, P.C.O.; ALVES, A.C.; LUZ, P.H. de C.; HERLING, V.R. Métodos para avaliar as perdas de nitrogênio por volatilização da superfície do solo e por emissão de amônia pela folhagem de Brachiaria brizantha cv. Marandu. São Carlos: Embrapa Pecuária Sudeste, 2008. 41p. (Embrapa Pecuária Sudeste. Boletim de pesquisa e desenvolvimento, 16).

PAIVA, D.M. de; CANTARUTTI, R.B.; GUIMARÃES, G.G.F.; SILVA, I.R. da. Urea coated with oxidized charcoal reduces ammonia volatilization. Revista Brasileira de Ciência do Solo, v.36,p.1221-1229, 2012. DOI: 10.1590/S0100-06832012000400016.

TASCA, F.A.; ERNANI, P.R.; ROGERI, D.A.; GATIBONI, L.C.; CASSOL, P.C. Volatilização de amônia do solo após a aplicação de ureia convencional ou com inibidor de urease. Revista Brasileira de Ciência do Solo, v.35, p.493-502, 2011. DOI: 10.1590/S010006832011000200018 .

Recebido em 31 de agosto de 2015 e aprovado em 9 de março de 2016 